\title{
Effects of glutamine supplementation on innate immune response in rats with gut-derived sepsis
}

\author{
Sung-Ling Yeh ${ }^{1}$, Yu-Ni Lai ${ }^{1}$, Huey-Fang Shang ${ }^{2}$, Ming-Tsan Lin $^{3}$ and Wei-Jao Chen ${ }^{3 *}$ \\ ${ }^{1}$ Institute of Nutrition and Health Sciences and \\ ${ }^{2}$ Department of Microbiology and Immunology, Taipei Medical University, Taipei, Taiwan, Republic of China \\ ${ }^{3}$ Department of Surgery, College of Medicine, National Taiwan University, Taipei, Taiwan, Republic of China
}

(Received September 2003 - Revised 4 November 2003 - Accepted 6 November 2003)

\begin{abstract}
The present study examined the effect of glutamine (Gln)-enriched diets before sepsis or Gln-containing total parenteral nutrition (TPN) after sepsis, or both, on the phagocytic activity and blood lymphocyte subpopulation in rats with gut-derived sepsis. Rats were assigned to a control group or one of four experimental groups. The control group and groups 1 and 2 were fed a semipurified diet; groups 3 and 4 had part of casein replaced by Gln. After feeding the diets for $10 \mathrm{~d}$, sepsis was induced by caecal ligation and puncture (CLP); TPN was maintained for $3 \mathrm{~d}$ after CLP. The control group and groups 1 and 3 were infused with conventional TPN and groups 2 and 4 were supplemented with Gln in the TPN solution. All rats were killed $3 \mathrm{~d}$ after CLP or sham operation to examine their immune responses. The results showed that compared with the control group, the phagocytic activities of peritoneal macrophages were enhanced in groups 3 and 4 , but not in groups 1 and 2 . The proportion of $\mathrm{CD}^{+}$cells in group 1 was significantly lower $(P<0.05)$ than that of the control group, whereas no differences were observed among the control and Gln-supplemented groups. The $\mathrm{CD} 4^{+}$cell proportion was significantly lower $(P<0.05)$ in group 1 compared with the control group and groups 3 and 4 . These findings suggest that Gln-enriched diets before CLP significantly enhanced peritoneal macrophage phagocytic activity, preserved $\mathrm{CD} 4^{+}$cells and maintained blood total $\mathrm{T}$ lymphocytes in gut-derived sepsis. However, parenteral Gln administration after caecal ligation and puncture had no favourable effects on modulating immune response in septic rats.
\end{abstract}

Glutamine: Gut-derived sepsis: Phagocytosis: Lymphocyte subpopulation

Glutamine (Gln) is the most abundant free amino acid in plasma and muscle and is an integral substrate in numerous metabolic functions (Smith \& Wilmore, 1990; Souba, 1991). A variety of animal and human trials has demonstrated that Gln has immuno-enhancing properties (Calder, 1994; Heberer et al. 1996; Gismondo et al. 1998; Wilmore \& Shabert, 1998). Previous reports have revealed that a relatively Gln-deficient state is created by the catabolic process, and Gln supplementation can correct this nutritional deficiency and hence improve outcomes (Hammerquist et al. 1989; Gianotti et al. 1995). Gln is required during catabolic processes to manifest optimal tissue responses to catabolism, inflammation and infection (Lacey \& Wilmore, 1990).

Sepsis is a major cause of death in patients who have undergone surgery. Sepsis is initiated by bacteria and their related toxins. When bacterial toxins insult the body, profound alterations in both immune responses and organ functions occur (Zellweger et al. 1995). Previous studies have shown that when Gln-enriched total parenteral nutrition (TPN) was given to septic rats, they had better survival, improved $\mathrm{N}$ balance and increased protein synthesis, and better protection of the morphology of the intestinal mucosa (Ardawi, 1992; Naka et al. 1996). Wischmeyer et al. (2001) demonstrated that Gln attenuated pro-inflammatory cytokine release and protected against end-organ damage in a rat model of endotoxin-induced septic shock. In addition, the study by Gianotti et al. (1995) showed that oral Gln supplementation decreases bacterial translocation in experimental gut-origin sepsis. Gln is an important fuel for lymphocytes and macrophages (Parry-Billings et al. 1990). Macrophages and neutrophils are involved in the early, non-specific host-defence responses and play an important role in the pathophysiology and/or protection against sepsis (Sawyer et al. 1989; Ringer \& Zimmerman, 1992). Previous reports showed that during inflammatory states such as sepsis and injury, the consumption of Gln by circulating and immune cells increases (Askanazi et al. 1980; Roth et al. 1982; Hammerquist et al. 1989). Studies have revealed that supplemental Gln augments the in vitro bactericidal activity of neutrophils in burned or postoperative patients (Ogle et al. 1994; Furukawa et al. 2000). Parry-Billings et al. (1990) reported that depressed Gln concentrations were associated with reduced phagocytosis

\footnotetext{
Abbreviations: CLP, caecal ligation and puncture; Gln, glutamine; HBSS, Hanks' balanced salt solution; RPMI, Rosswell Park Memorial Institute; TPN, total parenteral nutrition.

* Corresponding author: Dr Wei-Jao Chen, fax +88622341 2969, email chenwj@ccms.ntu.ed.tw
} 
by murine peritoneal macrophages. To our knowledge, there has not been any investigation of the effects of Gln on the innate immune responses in gut-derived sepsis. Therefore, our aim was to investigate the effect of Gln supplementation before, after, and both before and after sepsis, on the phagocytic activity of peritoneal macrophages; this is thought to be critical for killing translocated enteric bacteria in septic mice (sepsis induced by caecal ligation and puncture (CLP; Ringer \& Zimmerman, 1992; Matsukawa et al. 2000). In addition, the proportion of systemic lymphocytes and cytokines released from splenocytes after mitogen stimulation was analysed to investigate the possible role of Gln on modulating immune response in a septic condition.

\section{Materials and methods}

\section{Animals}

Male Wistar rats aged 8 weeks and weighing 200-230 g were used in the present study. All rats were housed in temperature- and humidity-controlled rooms and were allowed free access to standard rat chow for 1 week before the experiment. The care of the animals followed the guidelines for the care and use of laboratory animals established by the Taiwan University Hospital, and protocols were approved by the Animal Care Committee.

\section{Study protocol}

Rats were randomly assigned to a control group or one of four experimental groups. The control group and experimental groups 1 and 2 were fed a common semipurified diet. Rats in experimental groups 3 and 4 were fed an identical diet except that part of the casein was replaced by Gln, which provided $25 \% \mathrm{~N}$ (Table 1). After feeding rats the respective diets for $10 \mathrm{~d}$, sepsis in the experimental groups was induced by CLP, whereas the control group

Table 1. Composition of the semipurified diet $(\mathrm{g} / \mathrm{kg})^{\star}$

\begin{tabular}{lcc}
\hline Ingredients & Gln-supplemented & Without Gln \\
\hline Casein & 165 & 220 \\
Gln & 45 & - \\
Maize starch & 667 & 657 \\
Soyabean oil & 44 & 44 \\
Vitamin mixture† & 10 & 10 \\
Salt mixtureł & 35 & 35 \\
Methyl-cellulose & 30 & 30 \\
Choline chloride & 1 & 1 \\
DL-Methionine & 3 & 3 \\
\hline
\end{tabular}

* Total N: Gln supplemented $34.4 \mathrm{~g} / \mathrm{kg}$; without Gln $34.4 \mathrm{~g} / \mathrm{kg}$.

†The vitamin mixture contained the following $(\mathrm{mg} / \mathrm{g})$ : thiamin hydrochloride 0.600 , riboflavin 0.600 , pyridoxine hydrochloride 0.700 , nicotinic acid 3.000 , calcium pantothenate 1.600 , D-biotin 0.020 , cyanocobalamin 0.001 , retinyl palmitate 1.600 , DL- $\alpha-$ tocopheryl acetate $20 \cdot 000$, cholecalciferol 0.250 , and menaquinone 0.005 .

$\ddagger$ The salt mixture contained the following $(\mathrm{mg} / \mathrm{g})$ : calcium phosphate diabasic 500.00 , sodium chloride 74.00 , potassium sulfate 52.00 , potassium citrate monohydrate 220.00 , magnesium oxide 24.00 , manganese carbonate 3.50 , ferric citrate 6.00 , zinc carbonate 1.60 , cupric carbonate 0.30 , potassium iodate 0.01 , sodium selenite 0.01 , chromium potassium sulfate 0.55 underwent a sham operation. CLP was performed according to the method of Wichterman et al. (1980). Briefly, rats were anaesthetized with intraperitoneal pentobarbital $(50 \mathrm{mg} / \mathrm{kg})$, and the abdomen was opened through a midline incision. The caecum was isolated, and a 3-0 silk ligature was placed around it, ligating the caecum just below the ileo-caecal valve. The caecum was then punctured twice with an 18-gauge needle and was replaced back into the abdomen. The abdominal wound was closed in layers. Immediately after the sham or CLP operation, all rats underwent placement of a catheter for TPN infusion. A silicon catheter (Dow Corning, Midland, MI, USA) was inserted into the right internal jugular vein. The distal end of the catheter was tunnelled subcutaneously to the back of the neck, and exited through a coiled spring, which was attached to a swivel allowing free mobility of animals inside individual cages. TPN was administered at a rate of $2 \mathrm{ml} / \mathrm{h}$ the first day. Full-strength TPN (56$64 \mathrm{ml} / \mathrm{d}$, according to the body weight) was given thereafter, and continued for a period of $3 \mathrm{~d}$. The infusion speed was controlled by a Terufusion pump (model STC503; Terumo, Tokyo, Japan). The TPN solution without fat was prepared in a laminar-flow hood. Sterilized fat emulsions were added to the TPN solution daily just before use. The TPN solution was infused for the entire day at room temperature. All animals were allowed to drink water freely, and no enteral nutrition was administered during the period of TPN. The control group and experimental groups 1 and 3 were infused with conventional TPN. Experimental groups 2 and 4 were supplemented with Gln, which provided $25 \%$ total amino acid-N in the TPN solution. The TPN provided $1171 \mathrm{~kJ}(280 \mathrm{kcal}) / \mathrm{kg}$ body weight per $\mathrm{d}$, and the energy $(\mathrm{kJ}(\mathrm{kcal})): \mathrm{N}(\mathrm{g})$ ratio was 502 (120):1. The TPN solutions were isonitrogenous and identical in nutrient composition except for the difference in the amino acid content (Table 2). There were five groups of rats in this study: the control group,

Table 2. Composition of the total parenteral nutrition solution $(\mathrm{ml} / \mathrm{l})$

\begin{tabular}{lcc}
\hline & Gln-supplemented & Without Gln \\
\hline Glucose $(500 \mathrm{~g} / \mathrm{l})$ & 418 & 412 \\
Fat emulsion $(200 \mathrm{~g} / \mathrm{l})$ & 50 & 50 \\
Moriamin-SN $(100 \mathrm{~g} / \mathrm{l})^{*}$ & 417 & 556 \\
Gln & $11 \ddagger$ & - \\
Infuvita† & 8 & 8 \\
$\mathrm{NaCl}(30 \mathrm{~g} / \mathrm{l})$ & 35 & 35 \\
$\mathrm{KCl}(70 \mathrm{~g} / \mathrm{l})$ & 10 & 10 \\
$\mathrm{~K}_{3} \mathrm{PO}_{4}(87 \mathrm{~g} / \mathrm{l})$ & 10 & 10 \\
$\mathrm{Calcium}_{\mathrm{glu}}$ & 10 & 10 \\
$\mathrm{MgSO}_{4}$ & 4 & 4 \\
ZnSO $_{4}$ & 2 & 2 \\
Choline chloride & $1 \ddagger$ & $1 \ddagger$ \\
\hline
\end{tabular}

* From Chinese Pharmaceuticals, Taipei, Taiwan. Contents (g/l): Leu 12.50, Ile 5.60, Lys acetate 12.40, Met 3.50, Phe 9.35, Thr 6.50, Trp 1.30, Val 4.50, Ala 6.20, Arg 7.90, Asp 3.80, Cys 1.00, Glu 6.50, His 6.00, Pro 3.30, Ser 2.20, Tyr 0.35, aminoacetic acid (Gly) 15.70.

†From Yu-Liang Pharmaceuticals, Taoyuan, Taiwan. Contents (per ml) ascorbic acid $20 \mathrm{mg}$, vitamin A $660 \mathrm{IU}$, ergocalciferol $0.025 \mu \mathrm{g}$, thiamin hydrochoride $0.6 \mathrm{mg}$, riboflavin $0.72 \mathrm{mg}$, niacinamide $8 \mathrm{mg}$, pyridoxine hydrochloride $0.8 \mathrm{mg}$, D-panthenol $3 \mathrm{mg}$, DL- $\alpha$-tocopheryl acetate $2 \mathrm{mg}$, biotin $12 \mu \mathrm{g}$, folic acid $80 \mu \mathrm{g}$, cyanocobalamin $1 \mu \mathrm{g}$. 
not Gln-supplemented before or after the sham operation; group 1, not Gln-supplemented before or after CLP $(-/-)$; group 2, a semipurified diet given before and Gln-containing TPN after CLP $(-/+)$; group 3, a Glnenriched diet given before and conventional TPN after CLP (+/-); group 4, a Gln-enriched diet given before and Gln-containing TPN after CLP $(+/+)$.

\section{Measurements and analytical procedures}

TPN was given until the time of killing on day 3 after CLP. The surviving rats were weighed and anaesthetized. A middle abdominal incision was made, and $10 \mathrm{ml}$ PBS was injected intraperitoneally to elute the peritoneal cells. After harvesting the peritoneal lavage fluid, rats were killed by drawing arterial blood from the abdominal aorta. Fresh peritoneal lavage fluid was used for macrophage cell counts and phagocytic activity analysis. Heparinized whole blood was used for analysing the lymphocyte subpopulation and neutrophil phagocytosis. Plasma was centrifuged from the remaining blood; it was stored at $-80^{\circ} \mathrm{C}$ for analysis of amino acid concentrations.

\section{Plasma amino acid analysis}

Blood samples were collected in tubes containing heparin and were centrifuged to separate the plasma. All plasma samples were stored at $-70^{\circ} \mathrm{C}$ until assay. After thawing, plasma samples were deproteinized with salicylic acid (50 g/l); plasma amino acids were analysed by standard ion-exchange chromatography with ninhydrin detection (model 6300; Beckman Instruments, Palo Alto, CA, USA) (Smith \& Panico, 1985).

\section{Lymphocyte subpopulation distribution}

Fluorescein-conjugated mouse anti-rat CD3 (Serotec, Oxford, UK) and phycoerythrin-conjugated mouse antirat CD45Ra (Serotec) mAbs were used to distinguish $\mathrm{T}$ cells and B cells, while fluorescein-conjugated mouse anti-rat CD8 and phycoerythrin-conjugated mouse anti-rat CD4 (Serotec) mAbs were used to determine the proportions of $\mathrm{T}$ helper cells and cytotoxic $\mathrm{T}$ cells respectively. Fresh blood $(100 \mu \mathrm{l})$ was incubated with fluorescein-labelled $\mathrm{mAbs}$ for $15 \mathrm{~min}$ at $4^{\circ} \mathrm{C}$. After this, erythrocytes were lysed with lysing buffer (Serotec). Fluorescence data were collected on $5 \times 10^{4}$ viable cells and analysed by flow cytometry (Coulter; Miami, FL, USA).

\section{Phagocytosis assay of blood polymorphonuclear neutrophils}

A flow cytometric phagocytosis test was used to evaluate the phagocytic activity of blood polymorphonuclear cells (Böhmer et al. 1992; Schiffrin et al. 1995). Heparinized whole blood $(100 \mu \mathrm{l})$ was pipetted onto the bottom of a $12 \times 75 \mathrm{~mm}$ Falcon polystyrene tube (Becton Dickinson, Oxford, CA, USA), which was then placed in an iced-water bath. Pre-cooled opsonized fluorescein isothiocyanate (FITC)-labelled Escherichia coli $(20 \mu \mathrm{l}$; Molecular Probes, Eugene, OR, USA) was added to each tube.
Control tubes remained on iced water, and assay samples were incubated for precisely $10 \mathrm{~min}$ at $37^{\circ} \mathrm{C}$ in a shaking water-bath. After incubation, samples were immediately placed in iced water, and $100 \mu l$ pre-cooled Trypan Blue (Sigma, St Louis, MO, USA) solution $(0.25 \mathrm{mg} / \mathrm{ml}$ citrate salt buffer, $\mathrm{pH} 4.4$ ) was added to quench the fluorescence of the bacteria merely adhering to the surface of the phagocytized cells. Cells were washed twice in Hanks' balanced salt solution (HBSS), and erythrocytes were lysed by the addition of fluorescence-activated cell sorter (FACS) lysing solution (Becton Dickinson). After an additional wash in HBSS, $100 \mu \mathrm{l}$ propidium iodide solution $(1 \mu \mathrm{g} /$ ml HBSS) was added to stain the nuclear DNA $10 \mathrm{~min}$ before the flow cytometric analysis. Phagocytosis analysis was performed by a flow cytometer (Coulter, Miami, FL, USA). In each sample, $10^{4}$ cells were measured. A live gate was set on the red (propidium iodide) fluorescence histogram during acquisition to include only those cells with a DNA content at least equal to human diploid cells. The number of cells with phagocytic activity did not exceed $6 \%$ at $0^{\circ} \mathrm{C}$. The phagocytic activity of blood polymorphonuclear cells was presented as the percentage of phagocytozing cells in the test samples.

\section{Quantitative phagocytosis assay of peritoneal macrophages}

Because the isolated peritoneal macrophages tend to aggregate and adhere to the culture plates and the adherent macrophages have stronger phagocytic activity than those suspended in solution, we used a Vybrant ${ }^{\mathrm{TM}}$ phagocytosis assay kit (Molecular Probes, Eugene, OR, USA) rather than the flow cytometric method to evaluate the phagocytic activity of peritoneal macrophages. Peritoneal macrophages were harvested from peritoneal lavage fluid. The pellets were washed three times with HBSS. The cell number was adjusted to $10^{6}$ cells $/ \mathrm{ml}$ with Rosswell Park Memorial Institute (RPMI)-1640 supplemented with fetal bovine serum $(50 \mathrm{ml} / \mathrm{l})$ and an adequate amount of antibiotics. After distributing $100 \mu$ l diluted cells into each well of a ninety-six-well microplate, the plate was transferred to a $\mathrm{CO}_{2}$ incubator at $37^{\circ} \mathrm{C}$ for $1 \mathrm{~h}$ to allow the cells to adhere to the microplate surface. The RPMI solution was removed from all microplate wells by vacuum aspiration, and then $100 \mu \mathrm{l}$ of the prepared FITC-labelled $E$. coli was added to each well for $2 \mathrm{~h}$. Labelled bacteria were removed by vacuum aspiration, and $100 \mu l$ Trypan Blue suspension was added to all wells within $1 \mathrm{~min}$. The excess Trypan Blue was immediately aspirated, and the experimental and control wells (without peritoneal macrophages) were read in the fluorescence plate reader using about $480 \mathrm{~nm}$ for excitation and about $520 \mathrm{~nm}$ for emission.

\section{In vitro cultures of splenocytes}

Splenocytes were obtained by mechanical disruption of the spleen with a spatula on a stainless-steel mesh. Cell suspensions were passed through a sterile nylon mesh to remove debris. Erythrocytes were lysed using sterile distilled water for $15 \mathrm{~s}$ and immediately neutralized to isotonic cell suspensions. After washing with PBS three times 
( $300 \mathrm{~g}$ for $5 \mathrm{~min}$ ), splenocytes were resuspended in RPMI1640 with antibiotics and fetal calf serum. The number of isolated splenocytes was determined by a haemocytometer count using the Trypan Blue dye exclusion method.

\section{Cytokine assay}

Phytohaemagglutinin ( $200 \mathrm{ng} / \mathrm{ml}$; Sigma, St Louis, MO, USA) was used to stimulate cytokine production by isolated splenocytes in culture. Triplicate wells of ninetysix-well flat-bottomed microtitre plates (Falcon; Becton Dickinson) were seeded with splenocytes $\left(2.5 \times 10^{6}\right.$ cells/ ml RPMI-1640) and mitogen. The control well contained cells plus an equal volume of medium. After incubating phytohaemagglutinin for $24 \mathrm{~h}$ at $37^{\circ} \mathrm{C}$ in a $\mathrm{CO}_{2}$ incubator, supernatant fractions were centrifuged and stored at $-70^{\circ} \mathrm{C}$ until being analysed for cytokine. IL-2, IL-4, IL-10 and interferon- $\gamma$ concentrations in the supernatant fractions of phytohaemagglutinin-stimulated splenocytes were determined by commercially available ELISA kits (Amersham Pharmacia Biotech, Bucks., UK).

\section{Statistical analyses}

Results are expressed as the mean values and standard deviations. Differences among groups were analysed by one-way ANOVA using Fisher's test. A $P$ value of $<0.05$ was considered statistically significant.

\section{Results}

There were no differences in initial body weights, body weights after feeding the experimental diets for $10 \mathrm{~d}$ and body weights after TPN administration for $3 \mathrm{~d}$ among the five groups (results not shown). The Gln-supplemented groups had significantly higher plasma Gln concentrations (group 2498.0 (SD 50.4), group $3473 \cdot 1$ (SD 50.1), group 4 481.7 (SD 55.0) $\mathrm{nmol} / \mathrm{ml}$ ) than did group 1 (378.9 (SD 42.9) $\mathrm{nmol} / \mathrm{ml})$; there were no significant differences from the control group value (483.9 (SD 61.5) $\mathrm{nmol} / \mathrm{ml})$.

CLP may induce the migration of macrophages to the peritoneal cavity: the cell numbers of peritoneal

Table 3. Number of macrophages in peritoneal lavage fluid and phagocytic activity of peritoneal macrophages $\S$

(Mean values and standard deviations for rats per group)

\begin{tabular}{|c|c|c|c|c|c|}
\hline \multirow[b]{3}{*}{ Control } & \multirow{3}{*}{$\frac{n}{9}$} & \multicolumn{2}{|c|}{$\begin{array}{l}\text { Macrophages } \\
\left(\times 10^{6} \text { cells } / \mathrm{ml}\right)\end{array}$} & \multirow{2}{*}{\multicolumn{2}{|c|}{$\begin{array}{l}\text { Phagocytic } \\
\text { activity\|l }\end{array}$}} \\
\hline & & \multirow{2}{*}{$\frac{\text { Mean }}{1 \cdot 72}$} & \multirow{2}{*}{$\frac{S D}{1.02}$} & & \\
\hline & & & & 220.9 & $175 \cdot 0$ \\
\hline Group $1(-1-)$ & 11 & $5 \cdot 44^{*}$ & 1.09 & $630 \cdot 5$ & $530 \cdot 3$ \\
\hline Group $2(-1+)$ & 9 & $3 \cdot 22$ & 1.4 & $907 \cdot 0$ & $504 \cdot 3$ \\
\hline Group $3(+1-)$ & 9 & $6 \cdot 30^{*} \ddagger$ & $4 \cdot 17$ & $1830 \cdot 6^{*} \dagger$ & $1492 \cdot 6$ \\
\hline Group $4(+/+)$ & 11 & $4 \cdot 13$ & 2.77 & $2086 \cdot 1^{\star} \dagger \ddagger$ & $1374 \cdot 1$ \\
\hline
\end{tabular}

Mean values were significantly different from those of the control group: ${ }^{*} P<0.05$.

Mean values were significantly different from those of group 1: $\dagger P<0.05$.

Mean values were significantly different from those of group 2 : $\ddagger P<0.05$.

$\S$ For details of diets, groups, treatments and procedures, see Tables 1 and 2 p. 424.

|| Fluorescein on excitation $485 \mathrm{~nm}$, emission $535 \mathrm{~nm}$; for details, see p. 425 . macrophages were similar in groups $2(-/+)$ and $4(+/$ $+)$ and the control group. Groups $1(-/-)$ and $3(+/-)$ had higher peritoneal macrophage numbers than the control group. The phagocytic activity of peritoneal macrophages was significantly higher $(P<0.05)$ in group $4(+/+)$ than in other groups, except group $3(+/-)$. Group 3 had higher phagocytic activity than in the control group and groups $1(-/-)$, whereas there were no differences among the control group, group $1(-/-)$ and $2(-/+)$ (Table 3). However, there were no differences in the phagocytic activities of blood polymorphonuclear cells among all groups by flow cytometric phagocytosis analysis (control 55.1 (SD 27.0), group $1(-/-) 55 \cdot 1$ (SD 27.0), group $2(-/+) 52.6$ (SD 19.7), group $3(+/-) 57 \cdot 1$ (SD 24.6), group $4(+/+) 53 \cdot 1($ SD $25 \cdot 7) \%$.

The proportions of $\mathrm{CD}^{+}$cells in the blood in group 1 $(-/-)$ was significantly lower than that of the control group, whereas no differences were observed among the control and Gln-supplemented groups. The $\mathrm{CD}^{+}{ }^{+}$cell proportion was significantly lower $(P<0.05)$ in group 1 than those of the control group or groups $3(+/-)$ and $4(+/$ $+)$. There were no differences in the proportions of blood $\mathrm{CD}^{+}$cells among all groups. No differences were observed in $\mathrm{CD} 45 \mathrm{Ra}^{+}$proportion among the control and experimental groups except for group $4(+/+)$. Group 4 had a higher proportion of CD45Ra ${ }^{+}$than the control group (Fig. 1).

There were no differences in IL-2, IL-10 and interferon- $\gamma$ production among the five groups (Table 4 ) and IL-4 was not detectable when splenocytes were stimulated with mitogen.

The survival rates were higher in the control group $(100 \%)$ than the experimental groups. No differences in survival rates were observed among the four experimental groups $3 \mathrm{~d}$ after CLP (group $1(-/-)$ 64.7, group $2(-/+)$ $69 \cdot 2$, group $3(+/-) 71 \cdot 4$, group $4(+/+) 68 \cdot 8 \%)$.

\section{Discussion}

In the present study, $25 \%$ total $\mathrm{N}$ in the diet or TPN solution was supplied by Gln. This amount of Gln was

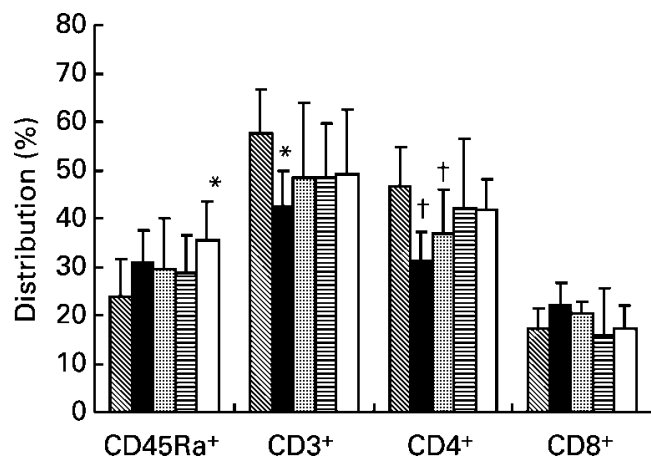

Fig. 1. Distributions of blood CD45Ra ${ }^{+}, \mathrm{CD}^{+}, \mathrm{CD}^{+}$, and $\mathrm{CD} 8^{+}$ lymphocytes among the control and experimental groups $3 \mathrm{~d}$ after caecal ligation and puncture. $\mathbb{Q}$, Control group $(n 9) ; \mathbf{a}$, group 1 $(-/-; n 11)$; 國, group $2(-/+; n 9)$; 目, group $3(+/-; n 9) ; \square$, group $4(+/+; n$ 11). For details of diets, groups, treaments and procedures, see Tables 1 and 2 and p. 424. Values are means with standard deviations shown by vertical bars. Mean values were significantly different from those of the control group: ${ }^{\star} P<0.05$. Mean values were significantly different from those of groups 3 and 4 : $\dagger P<0.05$. 
Table 4. The concentrations of IL-2, IL-10 and interferon (IFN)- $\gamma$ $(\mathrm{pg} / \mathrm{ml})$ released by splenocytes after phytohaemagglutinin stimulation for $24 \mathrm{~h}^{*} \dagger$

(Mean values and standard deviations for rats per group)

\begin{tabular}{|c|c|c|c|c|c|c|c|}
\hline & \multirow[b]{2}{*}{$n$} & \multicolumn{2}{|c|}{ IL-2 } & \multicolumn{2}{|c|}{ IL-10 } & \multicolumn{2}{|c|}{ IFN- $\gamma$} \\
\hline & & Mean & $\overline{S D}$ & Mean & SD & Mean & SD \\
\hline Con & 9 & $4 \cdot 2$ & $11 \cdot 3$ & $91 \cdot 2$ & 50.9 & $5 \cdot 2$ & $1 \cdot 1$ \\
\hline Group $1(-/-)$ & 11 & 23.7 & $5 \cdot 8$ & $165 \cdot 1$ & 138.9 & 8.4 & $6 \cdot 0$ \\
\hline Group $2(-1+)$ & 9 & 22.5 & $17 \cdot 9$ & $169 \cdot 8$ & $108 \cdot 5$ & $8 \cdot 2$ & 200 \\
\hline Group $3(+1-)$ & 9 & 20.9 & $13 \cdot 2$ & $192 \cdot 6$ & 193.1 & 9.7 & $7 \cdot 7$ \\
\hline Group $4(+1+)$ & 11 & $19 \cdot 4$ & $12 \cdot 4$ & 129.4 & $175 \cdot 0$ & $6 \cdot 5$ & $2 \cdot 8$ \\
\hline
\end{tabular}

${ }^{*}$ For details of diets, groups, treatments and procedures, see Tables 1 and 2 and p. 424.

$\dagger$ No significant differences were seen among the groups.

previously found to enhance the immune response in healthy rodents (Kew et al. 1999; Wells et al. 1999). We provided oral Gln supplementation for $10 \mathrm{~d}$ before sepsis was induced. This model mimics the septic complications in patients with abdominal surgery, in whom preventive use of a Gln-supplemented enteral diet may be recommended. TPN was administered after CLP, because sepsis has been shown to cause histological damage and adversely affect the barrier and metabolic functions of the small intestine (Navaratnam et al. 1990; Gardiner \& Barbul, 1993). A study by Gardiner et al. (1995) showed that sepsis induced by CLP resulted in impaired intestinal amino acid uptake, so the parenteral rather than the enteral route of Gln therapy may have benefits for survival from septic insult. We used CLP as a sepsis model, because CLP is clinically relevant and is considered a simple and reproducible model of gut-derived sepsis in rats (Wichterman et al. 1980).

Results of phagocytic activity of peritoneal macrophages showed that a Gln-enriched diet before sepsis had beneficial effects on enhancing phagocytic activity. This result was consistent with in vitro studies, which showed that Gln augments phagocytosis by neutrophils from burned and postoperative patients (Ogle et al. 1994; Furukawa et al. 2000). An in vivo study by Shou \& Daly (1994) also showed that a Gln-enriched diet preserved peritoneal macrophage superoxide production and bacteria killing in a diet-induced bacteria translocation rat model. Since the reports demonstrating that Gln enhances phagocytosis were in vitro studies, or in vivo studies not involving sepsis, the present study is the first to show that Glnenriched diet before sepsis significantly enhanced peritoneal macrophage phagocytic activity in a gut-derived sepsis model. In the present study, we found that parenterally infused Gln after CLP had no favourable effect on peritoneal phagocytosis. The lack of effect of parenteral Gln might be linked to the very short period of administration. Polymorphonucleocytes are potent inflammatory cells, and both the total number and percentage of circulating polymorphonucleocytes can be increased by acute infection and endotoxin (Sawyer et al. 1989). The phagocytic activity of blood polymorphonuclear cells did not differ among all groups in the present study. Since the peritoneal cavity is the primary site of injury, it is possible that
Gln stimulated phagocytic activity at the site of bacterial invasion. The effect of Gln on phagocytic cells in the systemic circulation was not obvious.

In order to understand the effect of Gln on the distribution of systemic total B cells $\left(\mathrm{CD} 45 \mathrm{Ra}^{+}\right)$, total T cells $\left(\mathrm{CD}^{+}\right)$, helper $\mathrm{T}\left(\mathrm{CD}^{+}\right)$, and cytotoxic $\mathrm{T}$ cells $\left(\mathrm{CD}^{+}\right)$ in septic rats, the subpopulations of lymphocytes were evaluated. The current work demonstrated that CLP with conventional TPN $(-/-)$ resulted in lower numbers of total $\mathrm{T}$ and $\mathrm{CD} 4^{+}$cells. Oral or parenteral Gln supplementation maintained total $\mathrm{T}$ lymphocytes, and a Gln-enriched diet before CLP $(+/-,+/+)$ preserved CD ${ }^{+}$cells. These results are similar to previous reports. A study by Kew et al. (1999) showed that supplemental dietary Gln resulted in increased proportions of $\mathrm{CD}^{+}$and $\mathrm{CD}^{+}$cells in the spleen of normal mice. Alverdy et al. (1992) also reported that Gln-enriched TPN maintained B and T cell populations in gut lamina propria of normal rats at levels similar to chow-fed animals. In the present study, we found that Gln supplementation both before and after CLP significantly increased systemic B cell distribution. A study by Kudsk et al. (2000) revealed that, compared with conventional TPN, normal mice with Gln-enriched TPN had improved respiratory and intestinal IgA levels. Whether Gln supplementation both before and after CLP enhances humoral immunity in septic conditions requires further investigation.

Cytokines are peptides produced by cells of the immune system that act as mediators of the immune response. According to our previous observations, IL-2 and interferon- $\gamma$ levels in plasma and peritoneal lavage fluid were not detectable in this septic model (Yeh et al. 2001). Therefore, we analysed the production of cytokines including IL-2, IL-4, IL-10 and interferon- $\gamma$ by splenocytes after mitogen stimulation to investigate the effect of Gln supplementation on the systemic immune response. IL- 2 and interferon- $\gamma$ are produced by Th1 lymphocytes. Th1 cytokines enhance cell-mediated immunity. Th2 cytokines, including IL-4 and IL-10, enhance humoral immunity. The effects of Th1 or Th2 lymphocytes are counter-regulatory (Parronchi et al. 1992; DiPiro, 1997). The findings showed that IL-4 levels were not detectable, and IL-2, IL-10 and interferon- $\gamma$ did not differ among groups after mitogen stimulation. This finding may indicate that Gln had no effect on modulating the production of cytokines under the present experimental conditions. Similarly, Kew et al. (1999) reported that Gln supplementation did not influence IL-4, IL-10 or interferon- $\gamma$ production. However, IL-2 production was increased in mouse splenocytes when Gln was administered. An in vitro study by Rohde et al. (1996) showed that Gln enhanced the production of IL- 2 and interferon- $\gamma$ by human blood mononuclear cells. Since in these studies the samples used for evaluating the effect of Gln on cytokine production were derived from healthy volunteers and normal mice, very different conditions from the present study and consequently possibly leading to different immune responses. Considering that in vitro splenocyte stimulation might not reflect actual in vivo situations, quantitation of cytokine mRNA expression in the spleen is now under investigation in our laboratory. 
In summary, the present study showed for the first time that enteral Gln-enriched diets before CLP significantly enhanced peritoneal macrophage phagocytic activity, preserved $\mathrm{CD}^{+}$cells and maintained blood total T lymphocytes in a gut-derived sepsis model. Gln administered both before and after CLP increased the systemic B cell distribution. However, parenteral Gln administration after CLP had no favourable effects on modulating immune response in septic rats. In addition, no significant benefit on survival was observed in Gln-supplemented rats with gut-derived sepsis. We speculate that Gln predominantly augments the immune response at the site of the injurious stimulus, and that the effect of Gln on the systemic immune response might not be potent enough to evoke a survival benefit under the present experimental condition. Since survival was only observed for $3 \mathrm{~d}$ in the present study, determining whether Gln supplementation improves survival over a longer period requires further investigation.

\section{Acknowledgements}

This study was supported by research grant NSC 91-2320B-038-017 from the National Science Council, Republic of China.

\section{References}

Alverdy JA, Aoys E, Weiss-Carrington P \& Burke DA (1992) The effect of glutamine-enriched TPN on gut immune cellularity. J Surg Res 52, 34-38.

Ardawi MS (1992) Effects of epidermal growth factor and glutamine-supplemented parenteral nutrition on the small bowel of septic rats. Clin Sci 82, 573-580.

Askanazi J, Carpentier YA, Michelson CB, Elwyn DH, Furst P, Kantrowitz LR, Gump FE \& Kinney JM (1980) Muscle and plasma amino acids following injury. Influence of intercurrent infection. Ann Surg 192, 78-85.

Böhmer RH, Trinkle LS \& Staneck JL (1992) Dose effects of LPS on neutrophils in a whole blood flow cytometric assay of phagocytosis and oxidative burst. Cytometry 13, 525-531.

Calder PC (1994) Glutamine and the immune system. Clin Nutr $13,2-8$.

DiPiro JT (1997) Cytokine networks with infection: mycobacterial infections, leishmaniasis, human immunodeficiency virus infection, and sepsis. Pharmacotherapy 17, 205-223.

Furukawa S, Saito H, Inoue T, Matsuda T, Fukutsu K, Han I, Ikeda S \& Hidemura A (2000) Supplemental glutamine augments phagocytosis and reactive oxygen intermediate production by neutrophils and monocytes from postoperative patients in vitro. Nutrition 16, 323-329.

Gardiner K \& Barbul A (1993) Intestinal amino acid absorption during sepsis. J Parenter Ent Nutr 17, 277-283.

Gardiner KR, Gardiner RE \& Barbul A (1995) Reduced intestinal absorption of arginine during sepsis. Crit Care Med 23, $1227-1232$.

Gianotti L, Alexander JW, Gennari R, Pyles T \& Babcock GF (1995) Oral glutamine decreases bacterial translocation and improves survival in experimental gut-origin sepsis. J Parenter Ent Nutr 19, 69-74.

Gismondo MR, Drago L, Fassina MC, Vaghi I, Abbiati R \&
Grossi E (1998) Immunostimulating effect of oral glutamine. Dig Dis Sci 43, 1752-1754.

Hammerquist F, Wernerman J, Al R, Vonder D \& Vinners E (1989) Addition of glutamine to total parenteral nutrition after elective abdominal surgery spares glutamine in muscle, counteracts the fall in muscle protein synthesis and improves nitrogen balance. Ann Surg 209, 455-461.

Heberer M, Babst R, Juretic A, Gross T, Horig H, Harder F \& Spagnoli GC (1996) Role of glutamine in the immune response in critical illness. Nutrition 12, Suppl., S71-S72.

Kew S, Wells SM, Yaqoob P, Wallace FA, Miles EA \& Calder PC (1999) Dietary glutamine enhances murine T-lymphocyte responsiveness. J Nutr 129, 1524-1531.

Kudsk KA, Wu Y \& Fukatsu K, Zarzaur BL, Johnson CD, Wang R \& Hanna MK (2000) Glutamine-enriched total parenteral nutrition maintains intestinal interleukin-4 and mucosal immunoglobulin A levels. J Parenter Ent Nutr 24, $270-275$.

Lacey JM \& Wilmore DW (1990) Is glutamine a conditionally essential amino acid? Nutr Rev 48, 297-309.

Matsukawa A, Hogaboam CM, Lukacs NW, Lincoln PM, Evanoff HL \& Kunkel SL (2000) Pivotal role of the CC chemokine, macrophage-derived chemokine, in the innate immune response. J Immunology 164, 5362-5368.

Naka S, Saito H, Hashiguchi Y, Lin MT, Furukawa S, Inaba T, Fukushima R, Wada N \& Muto T (1996) Alanyl-glutaminesupplemented total parenteral nutrition improves survival and protein metabolism in rat protracted bacterial peritonitis model. J Parenter Ent Nutr 20, 417-423.

Navaratnam RL, Morris SE, Traber DL, Flynn J, Woodson L, Linares \& Herndon DN (1990) Endotoxin (LPS) increases mesenteric vascular resistance (MVR) and bacterial translocation (BT). J Trauma 30, 1104-1113.

Ogle CK, Ogle JD, Mao JX, Simon J, Noel JG, Li BG \& Alexander JW (1994) Effect of glutamine on phagocytosis and bacterial killing in normal and pediatric burn patient neutrophils. J Parenter Ent Nutr 18, 128-133.

Parronchi P, DeCarli M, Manetti R, Simonelli C, Sampognaro S, Piccinni MP, Macchia D, Maggi E, Del Prete G \& Romagnani S (1992) IL-4 and IFN (alpha and gamma) exert opposite regulatory effects on the development of cytolytic potential of Th1 or Th2 human $\mathrm{T}$ cell clones. J Immunol 149, 2977-2983.

Parry-Billings M, Evans J, Calder PC \& Newsholme EA (1990) Does glutamine contribute to immunosuppression after major burns? Lancet 336, 523-525.

Ringer TV \& Zimmermann JJ (1992) Inflammatory host responses in sepsis. Crit Care Clinics 8, 163-189.

Rohde T, Maclean DA \& Klarlund Pedersen B (1996) Glutamine, lymphocyte proliferation and cytokine production. Scand $J$ Immunol 44, 648-650.

Roth E, Funovis J, Muhlbacher F, Schemper M, Mauritz W, Sporn P \& Fritsch A (1982) Metabolic disorders in severe abdominal sepsis: glutamine deficiency in skeletal muscle. Clin Nutr 1, 25-28.

Sawyer DW, Donowitz DR \& Mandell GL (1989) Polymorphonuclear neutrophils: an effective antimicrobial force. Rev Infect Dis 11, 1532-1544.

Schiffrin EJ, Rochat F, Link-Amster H, Aeschlimann JM \& Donnet-Hughes A (1995) Immunomodulation of human blood cells following ingestion of lactic acid bacteria. J Dairy Sci 78, 491-497.

Shou J \& Daly JM (1994) Enteral glutamine augments host immune function. Surg Forum 45, 33-34.

Smith RJ \& Panico K (1985) Automated analysis of $o$-phthalaldehyde derivatives of amino acids in physiological fluids of 
reverse phase high performance liquid chromatography. $J$ Liq Chromatogr 8, 1783-1795.

Smith RJ \& Willmore DW (1990) Glutamine nutrition and requirements. J Parenter Ent Nutr 14, 94S-99S.

Souba WW (1991) Glutamine: a key substrate for the splanchnic bed. Annu Rev Nutr 11, 285-308.

Wells SM, Kew S, Yaqoob P, Wallace FA \& Calder PC (1999) Dietary glutamine enhances cytokine production by murine macrophages. Nutrition 15, 881-884.

Wichterman KA, Baue AE \& Chaudry IH (1980) Sepsis and septic shock - a review of laboratory models and a proposal. J Surg Res 29, 189-201.
Wilmore DW \& Shabert JK (1998) Role of glutamine in immunologic responses. Nutrition 14, 618-626.

Wischmeyer PE, Kahana M, Wolfson R, Ren H, Musch MM \& Chang EB (2001) Glutamine reduces cytokine release, organ damage, and mortality in a rat model of endotoxemia. Shock 16, 398-402.

Yeh SL, Yeh CL, Lin MT, Lo PN \& Chen WJ (2001) Effects of glutamine-supplemented total parenteral nutrition on cytokine production and $\mathrm{T}$ cell population in septic rats. J Parenter Ent Nutr 25, 269-274.

Zellweger R, Ayala A, DeMaso CM \& Chaudry IH (1995) Trauma-hemorrhage causes prolonged depression in cellular immunity. Shock 4, 149-153. 